\title{
Identification of Seedling Vigor-Associated Quantitative Trait Loci in Temperate Japonica Rice
}

\author{
Karla I. Cordero-Lara ${ }^{1,2}$, HyunJung Kim ${ }^{1}$, Thomas H. Tai ${ }^{1,3} *$ \\ ${ }^{1}$ Department of Plant Sciences, University of California, Davis, CA 95616, USA \\ ${ }^{2}$ INIA CRI Quilamapu, Casilla 426, Chillán 3780000, Chile \\ ${ }^{3}$ USDA-ARS Crops Pathology and Genetics Research Unit, Davis, CA 95616, USA
}

\begin{abstract}
A quantitative trait loci (QTL) analysis of seedling vigor traits was conducted under dry-seeded conditions using 176 recombinant inbred lines developed from a cross of two California temperate japonica rice varieties M-203 and M-206. Height at early seedling (HES) and height at late seedling (HLS) stage, growth rate (GR), and fresh weight were evaluated in a growth chamber. Assessment of HES, HLS, and GR was also performed in outdoor basins in 2015 and 2016. M-203 was significantly better for all traits in the growth chamber, however, no significant differences were observed between the parents in the outdoor basins with the exception of HES in 2015. Genotyping by sequencing was used to construct a map of $>6,000$ single nucleotide polymorphisms. Six QTL were detected in the growth chamber, one each on chromosomes 2, 9, 10, and 12 and two at the same position on 1.qFW1 and $q H E S 1$ explain $34.6 \%$ and $8.7 \%$ of the phenotypic variation observed for their respective traits and correspond to previously reported QTL for shoot length. All positive effects were contributed by the M-203 allele except for the $q H L S 12$. Two QTL, $q H E S 8$ (12.3\%; M-206 allele) and qHES9 (9.4\%; M-203 allele), were detected in the outdoor basin 2016, but none in 2015. RIL-187 was consistently among the highest vigor lines in all environments and additional evaluations confirmed this finding. The molecular and genetic resources developed here will facilitate further investigation of seedling vigor and breeding of enhanced temperate japonica rice varieties.
\end{abstract}

Keywords Seedling vigor, Temperate japonica, Quantitative trait loci, Genotyping by sequencing, Rice

\section{INTRODUCTION}

More than half of the world's rice growing regions consist of irrigated ecosystems which account for $75 \%$ of global rice production (Mahender et al. 2015). Rice cultivation in much of this area is based on the transplantedpuddled rice (TPR) system. Advantages of the TPR system include reduced competition from weeds and good crop establishment as healthy, uniform rice seedlings are produced in nurseries for transplanting and the anaerobic conditions of the puddled soil promote increased access to nutrients (Mahender et al. 2015). However, TPR-based rice production is becoming unsustainable as water, labor and energy resources grow increasingly scarce (Farooq et al. 2011). The alternative to TPR is direct-seeded rice (DSR) cultivation. As the name implies, DSR involves sowing of seeds directly into soil (i.e., dry- or drill-seeding) or pre-germinated seeds into pre-flooded fields (i.e., water-seeding). DSR requires less labor and water resources than TPR. In the US, virtually all rice production involves DSR with dry-seeding predominantly employed in the southern US rice belt and water-seeding used almost

Received September 27, 2016; Revised November 10, 2016; Accepted November 16, 2016; Published November 30, 2016

*Corresponding author Thomas H. Tai, Thomas.Tai@ars.usda.gov, Tel: +1-530-752-4342, Fax: +1-530-754-7195

Mention of trade names or commercial products in this publication is solely for the purpose of providing specific information and does not imply recommendation or endorsement by the U.S. Department of Agriculture. USDA is an equal opportunity provider and employer. 
exclusively in California and in some parts of Louisiana. Good stand establishment is a major challenge for DSR cultivation since germinating seeds and developing seedlings are exposed to an array of abiotic and biotic stresses. Thus, strong seedling vigor is an important breeding objective for varieties used in DSR production systems.

Seedling vigor in rice has been associated with many quantitative traits (Redoña and Mackill 1996). Over the past twenty years or so, a large number of quantitative trait loci (QTL) for rice seedling vigor and associated traits have been detected in various studies (reviewed by Mahender $e t$ al. 2015). These traits include morphological (e.g., shoot length [SL] and root length [RL], fresh and dry weight), physiological (e.g., germination, chlorophyll content), and biochemical (e.g., amylase activity) characteristics. Genetic studies of rice seedling vigor have primarily involved analysis of biparental mapping populations (e.g., $F_{2}$, doubled haploid lines, recombinant inbred lines [RIL], backcross inbred lines) derived mainly from intersubspecific crosses (Redoña and Mackill 1996; Lu et al. 2007; Jiang et al. 2008; Cairns et al. 2009; Lee et al. 2012; Diwan et al. 2013; Manangkil et al. 2013). A very small number of studies have been reported in which populations derived from intrasubspecific crosses have been analyzed. These include indica/indica (Cui et al. 2002; Xie et al. 2014) and japonica/japonica (Yang et al. 2010; Abe et al. 2012) crosses. More recently, association mapping strategies have been employed to detect seedling vigor QTL in natural populations of rice varieties (primarily indica) and landraces (Dang et al. 2014; Cheng et al. 2015; Wu et al. 2015; Anandan et al. 2016; Lu et al. 2016).

Due to the complex, quantitative nature of seedling vigor and the different rice production systems employed around the world, there is no uniform standard for its evaluation and progress towards breeding improved varieties has been limited (Xie et al. 2014; Mahender et al. 2015). In California, rice is planted by sowing pre-germinated seeds into level fields which have just been flooded. Rapid growth of rice seedlings in the flooded fields is critical to stand establishment and all released varieties in California have good seedling vigor in a water-seeded production system (McKenzie et al. 2015). In this type of DSR system, shoots must grow rapidly to provide oxygen to the root systems and enable their establishment in the low oxygen environment of the rice paddy. In contrast, rice seeds that are dry-seeded are sown directly into soil which is then flushed with water to initiate germination. These seeds must be able to germinate rapidly in the soil. Under such conditions, rice roots develop more rapidly than in water-seeded systems and this is followed by shoot growth and emergence of seedlings from the soil.

As noted earlier, many of the studies on the genetic basis for seedling vigor in rice have been conducted using mapping populations derived from intersubspecific crosses (Mahender et al. 2015). While the results of these studies provide an important foundation for understanding the fundamental aspects of seedling vigor, they may be of limited use for breeding programs which typically concentrate on less diverse, elite germplasm. With breeding applications in mind, studies focusing on the identifying QTL expressed in populations derived from intrasubspecific crosses and on the analysis of large, unstructured populations of germplasm (i.e., association mapping) may be more useful in terms of the QTL detected and the resulting germplasm. The advent of ultra-high-throughput genotyping platforms based on single nucleotide polymorphism (SNP) markers has removed low marker coverage as a barrier to genetic mapping experiments in populations of reduced genetic diversity and also facilitated powerful genome-wide association studies to identify useful alleles within and among rice subpopulations (Spindel et al. 2013; Wu et al. 2015; Lu et al. 2016; McCouch et al. 2016).

Recently, we developed a RIL mapping population (M-2036 RIL population) from two California medium grain temperate japonica varieties, M-203 and M-206. Released in the late 1980s, M-203 is no longer in production but is used as breeding germplasm. M-206 is currently the most widely grown variety in California. M-203 and M-206 have similar seedling vigor in the water-seeding production environment. However, while evaluating these lines for various traits of interest, it was observed that under dry-seeding M-203 seedlings exhibited greater early vigor than M-206. In this study, we investigated the difference in seedling vigor between M-203 and M-206 under dry-seeded conditions by performing a QTL analysis of four seedling vigor-associated traits using the 
M-2036 RIL population. The population was planted for evaluation using direct-seeding into soil in both growth chamber and outdoor environments. Genotyping by sequencing (GBS) was employed to identify SNP markers and an ultra-high density linkage map was constructed from over 6,000 SNPs. The genetic map was used in conjunction with phenotypic data to identify putative QTL associated with the seedling vigor differences observed between these two temperate japonica parents.

\section{MATERIALS AND METHODS}

\section{Plant materials and DNA extraction}

M-203 and M-206 are semidwarf, medium grain temperate japonica cultivars developed by the California Cooperative Rice Research Foundation at the Rice Experiment Station (RES), Biggs, CA, USA. M-203 was selected as pure line from the $\mathrm{X} 2$ generation of M-401 seed irradiated with $25 \mathrm{kRad}$ of Cobalt ${ }^{60}$ (Carnahan et al. 1989). M-206 was developed from the cross S-301/M-204 (Johnson 2005) and is currently the leading variety grown in California. In 2009, $F_{2}$ seed from the cross M-203/M-206 was obtained from the RES medium grain rice breeding program (V. Andaya) and subsequently a RIL mapping population (M-2036; $\mathrm{n}=241$ ) was created using self-pollination under a scheme of singe seed descent. For this study, 176 RILs were used due to the limited space available for the various phenotyping experiments. Plants used for genotyping and phenotyping were derived from seeds increased in the RES nursery in Biggs, CA in 2012.

For genotyping, leaf tissue was harvested from two week-old seedlings of the M-2036 RIL population and total genomic DNA samples were prepared as described by Tai and Tanksley (1990) with the modification that the tissue was frozen with liquid nitrogen and ground using a metal nuts and a vortex. DNA concentrations were determined using a Synergy H1 multi-mode plate reader with a Take3 micro-volume plate (BioTek, Winooski, VT, USA). DNA quality was assessed by restriction enzyme digestion.

\section{Evaluation of seedling vigor-associated traits in the M-2036 RIL population}

Evaluation of seedling vigor-associated traits was performed on plants grown in growth chamber and outdoor basin environments. Seedlings grown in the growth chamber were evaluated for four seedling vigor-associated traits: height at early seedling (HES) stage; height at late seedling (HLS) stage; growth rate (GR); and fresh weight (FW) of aboveground biomass. HES and HLS were measured in $\mathrm{cm}$ from the surface of the soil to the tip of the longest leaf of each seedling. HES was measured seven days after sowing (DAS) at which time seedlings were at the two to three leaf stage. HLS was evaluated seven days after HES (i.e., 14 DAS). GR was calculated as GR= [HLS-HES]/7 and expressed in $\mathrm{cm} /$ day. After HLS measurement, the aboveground biomass of the seedlings was harvested and weighed (g).

For growth chamber-based phenotyping, eight seeds from each line and the two parents were sown in 50 cell plug flats containing Sunshine Mix \#1 (Sun Gro Horticulture, Agawam, MA, USA) that had been sieved to remove soil aggregates. A randomized complete block design (RCBD) with three replications was employed and the growth chamber phenotyping experiment was performed twice. Seeds were covered with soil and watered gently with deionized (DI) water to completely soak the soil. Flats were placed in 10 " $\times 20$ " plastic propagation trays and transferred to a Conviron PGR15 growth chamber (Controlled Environments Ltd., Winnipeg, MB, Canada) that was set at $28^{\circ} \mathrm{C}$ constant temperature, 12-hour photoperiod (7 AM-7 PM), and a photosynthetic photon flux density of 500 $\mu \mathrm{mol} \cdot \mathrm{m}^{-2} \mathrm{~s}^{-1}$. Flats were watered with DI water on a daily basis. After emergence, seedlings were thinned to five seedlings per cell of the plug flats. Plants were fertilized one time 10 DAS with a solution of Peters Professional Peat Lite Special ${ }^{\circledR}$ 15-16-17 Water Soluble fertilizer (Scotts Co., Marysville, OH, USA) and Sprint 330 iron chelate (Becker Underwood, Inc. Ames, IA, USA). Seedling heights were measured seven and 14 DAS.

Seedlings grown in the outdoor basins were evaluated for HES, HLS, and GR. Due to the outdoor environment, HES measurements were taken later than the growth 
chamber in order to evaluated seedlings at the two to three leaf stage. As with the growth chamber experiments, HLS was evaluated seven days after HLS. The M-2036 RIL population and parents were evaluated in May 2015 and June 2016 at the UC Davis Department of Plant Sciences, Field Headquarters, Davis, CA, USA. In both years, a RCBD with four replications was used. In 2015, one seed per line was planted in three and a half inch square pots (Kord Products, Toronto, ON, Canada) containing rice soil mix (Department of Plant Sciences, UC Davis). Four additional replications were planted as backups and used to replace any pots where seedlings did not emerge. Seedlings were fertilized 10 DAS using the same fertilizer as the growth chamber study. Plants were evaluated 12 and 19 DAS for HES and HLS, respectively. In 2016, three seeds were sown in four inch square pots (Kord Products) using the same soil mix and seedlings were thinned to one plant per pot after emergence (about seven to 10 DAS). Seedlings were fertilized 10 DAS with Miracle-Gro All Purpose Plant Food (Scotts Co., Marysville, OH, USA). Plants were evaluated 14 and 21 DAS for HES and HLS, respectively.

\section{SNP discovery and genotyping of M-2036 RILs using GBS}

Two 96-plex GBS libraries consisting of 190 RILs and the two parental lines were generated as described in Elshire et al. (2011) using the ApeKI restriction enzyme (Spindel et al. 2013). The TASSEL-GBS discovery pipeline (Glaubitz et al. 2014) was used for SNP calling and for alignment to the Nipponbare reference genome (MSU Rice Genome Annotation Project Release 7) (Kawahara et al. 2013) using Burrows-Wheeler aligner (BWA) (Li and Durbin 2009). Parameters to run the pipeline were as follows: 1) In each barcoded FASTQ file, all reads initiated with the appropriate barcode and restriction enzyme sites were detected and trimmed to 64 bases (termed "tag") using the FastqToTagCountPlugin (option: -c 1);2) multi tag files were merged into one master tag file and rare tags were removed using the MergeMultipleTagCountPlugin (option: -c 3); 3) the master tag file was converted to FASTA format for BWA to align to the rice reference genome using the
TagCountToFastqPlugin (option: -c 3); 4) After alignment, the resulting Sequence Alignment/Map (.sam) file was converted to a binary tagsOnPhysicalMap (.topm) file for SNP calling using the SAMConverterPlugin; 5) TagsByTaxa files were generated for each FASTQ file and the distribution of master tags among taxa was decided using the FastqToTBTPlugin (option: -c 1); and 6) Separated TagsByTaxa files were merged into a single file using the MergeTagsByTaxaFilesPlugin (option: -s 300,000,000). SNP genotype data containing 103,233 SNP sites were generated as a variant call format (.vcf) file. GBS and SNP calling was performed by the Genomic Diversity Facility, Institute of Biotechnology, Cornell University (Ithaca, NY, USA).

SNPs for QTL analysis were selected based on the fact that 1) polymorphisms existed between two parents, 2) the genotype was fully identified between two parents without any missing genotype information, 3) no heterozygous SNPs were in either parent, 4) minor allele frequency (MAF) was less than $1 \%, 5$ ) Mendelian error rate was less than $10 \%$, and 6) genotype rate per site was greater than $75 \%$. Filtration of the SNP dataset was conducted by Plink v1.07 (Purcell et al. 2007) and R/qtl v 1.39-5 (Broman et al. 2003) in R v3.3.1. Conversion between file formats was implemented by TASSEL v5 (Bradbury et al. 2007) and the customized R script. A total of 6,332 SNPs ( $91.1 \%$ of those genotyped) were selected for QTL analysis of the 176 RILs. Minor allele frequency of this final SNP dataset following filtration was $25 \%$. No genotype (line) was dropped based on $1 \%$ of Mendelian errors across all SNPs.

\section{Identification of putative QTLs for seedling vigor-associated traits}

Genetic linkage map construction and QTL analyses were performed as described in Spindel et al. (2013), using the publicly available QTL mapping code at http://www.ricediversity.org/data. Briefly, the R/QTL package (R v3.3.1, R/qtl package 1.39-5) was used to construct the genetic linkage map using the Kosambi mapping function and a single-marker QTL scan was performed using the scanone() function with Haley-Knott Regression. The logarithm of the odds (LOD) threshold for significance was determined based on 1,000 permutations. 
Following initial scan for QTLs, additional linked QTLs were detected by conditioning on the QTLs identified in the initial single-marker scan. The final QTL model was obtained by using step-wise forward selection and backward elimination to search the model space for the best fit for the data. The percentage of variance explained by each QTL and estimated effect sizes were calculated from an analysis of variance (ANOVA) analysis of the final QTL model. Peak marker positions and flanking SNP markers corresponding to the nearest marker within 1.5 LOD units of the peak position, representing the $95 \%$ confidence interval, are reported for each QTL. Due to the high marker density, this approach is comparable to composite interval mapping.

\section{Evaluation of seedling vigor-associated traits in high vigor RILs}

Nine RILs were selected based on the results of the seedling vigor evaluations of the M-2036 RIL population in the growth chamber and outdoor basin environments. Seven of these were classified as high seedling vigor (RIL-25, 138, 149, 172, 187, 196, and 231) and two as low seedling vigor (RIL-49 and 77) from the previous experiments. Seedlings were grown in a growth chamber under two conditions: 1) $28^{\circ} \mathrm{C}$ constant temperature, 12-hour photoperiod, and a photosynthetic photon flux density of $500 \mu \mathrm{mol} \cdot \mathrm{m}^{-2} \mathrm{~s}^{-1}$; 2) $28^{\circ} \mathrm{C}$ for eight hours followed by $13^{\circ} \mathrm{C}$ for 16 hours with the same lighting conditions (i.e., lights on during $28^{\circ} \mathrm{C}$ and for four out 16 hours of the $13^{\circ} \mathrm{C}$ ). Two seeds from each line were planted in rice soil mix in 12 ounce styrofoam cups which were arranged in a RCBD with four replications. Each cup was perforated six times in the lower peripheral area and five times in the bottom of the cup to facilitate watering. After seven days of growth, plants were thinned down to one plant per cup.

For these evaluations, six seedling-vigor associated traits were measured: SL, RL, shoot FW, root FW, dry shoot weight and root dry weight. SL was measured from the soil surface to the top of the longest leaf and RL was taken as the length of the longest root. Trait data were recorded seven and 14 DAS. Styrofoam cups were removed and the plants were triple washed with DI water and placed in sealable plastic bags for evaluation in the lab. Seedlings were measured (shoot and RL) and then the shoots were separated from roots and the FWs were measured. The shoots and roots were then placed in separate paper envelopes and dried at $65^{\circ} \mathrm{C}$ for 48 hours before recording dry weights. Each experiment was repeated twice.

\section{Statistical analyses of seedling vigor-associated trait data}

Descriptive statistical analyses including mean and standard deviation of the RIL population and mean differences between two parents based on Student's t-test were calculated in R. Linear correlations among seedling vigor traits were calculated based on Pearson's correlation coefficient using Hmisc v3.17-4 in R. ANOVA analyses were performed using SAS/STAT statistical package (version 9.4, SAS Institute Inc., Cary, NC, USA). Each trait under study in each experiment was analyzed separately. For lines, means separation multiple pairwise comparison tests were used, specifically the least significant difference test at level of confidence of $0.05(P=0.05)$.

\section{RESULTS}

\section{Evaluation of seedling vigor differences between M-203 and M-206}

In order to investigate differences in grain milling quality between the California medium grain rice varieties M-203 and M-206, a RIL population (M-2036 RILs) was developed from the cross M-203/M-206 by single seed descent $\left(\mathrm{F}_{7} ; \mathrm{n}=241\right)$. With the availability of this mapping population, the M-203 and M-206 lines were also evaluated for other traits of interest including seedling vigor. Preliminary assessment of seedling growth under dry-seeding conditions in a controlled environment (i.e., growth chamber) revealed possible differences in seedling vigor between the parental lines (SI Kim and TH Tai, unpublished observations). Phenotyping of the parents and a randomly selected subset of the M-2036 RIL population $(n=176)$ was subsequently performed in a growth chamber. M-203 exhibited significantly better performance than M-206 for plant height at early (7 DAS; HES) and late (14 
DAS; HLS) seedling stage, GR, and for FW of aboveground biomass (FW) (Table 1). A normal continuous distribution with transgressive segregation for all four traits was observed in the population (Fig. 1). In the case of HES and $\mathrm{FW}$, this transgressive segregation was only observed in the direction of the better performance than the better parent M-203. Broad-sense heritability values ranged from around $40 \%$ to $45 \%$ for HES and $\mathrm{FW}$ to $65 \%$ to $70 \%$ for

Table 1. Seedling vigor-related traits in the M-2036 recombinant inbred line (RIL) population ( $n=176)$ under different growing environments.

\begin{tabular}{lcrcc}
\hline \hline \multicolumn{1}{c}{ Environment/trait } & M-203 & M-206 & RIL population & Heritability $^{\mathrm{y})}$ \\
\hline Growth chamber $^{\mathrm{z}}$ & & & & \\
Height early seedling (cm) & $10.9 \pm 1.5^{*}$ & $5.5 \pm 0.2$ & $8.3 \pm 1(6.1-10.7)$ & 42.1 \\
Height late seedling (cm) & $41.6 \pm 1.4^{* *}$ & $34.3 \pm 0.3$ & $37.7 \pm 2.7(30.0-44.2)$ & 66.6 \\
Growth rate (cm/d) & $4.5 \pm 0.2^{*}$ & $3.7 \pm 0.3$ & $4.2 \pm 0.3(3.4-5)$ & 67.9 \\
Fresh weight (g) & $1.5 \pm 0.1^{* *}$ & $1.1 \pm 0.1$ & $1.4 \pm 0.1(1.1-1.6)$ & 45.0 \\
Outdoor basins 2015 & & & & \\
Height early seedling (cm) & $8.5 \pm 0.5^{* *}$ & $5.0 \pm 0.5$ & $6.8 \pm 1.3(3.3-10.5)$ & 21.9 \\
Height late seedling (cm) & $15.3 \pm 1.6$ & $12.8 \pm 1.4$ & $13.3 \pm 2.1(6.7-18.3)$ & 19.5 \\
Growth rate (cm/d) & $1.1 \pm 0.2$ & $1.0 \pm 0.1$ & $0.9 \pm 0.2(0.5-1.5)$ & 2.8 \\
Outdoor basins 2016 & & & & \\
Height early seedling (cm) & $14.8 \pm 1.5$ & $12.6 \pm 0.9$ & $12.7 \pm 1.1(9.9-15.5)$ & 21.5 \\
Height late seedling (cm) & $21.3 \pm 1.2$ & $20.8 \pm 1.0$ & $19.9 \pm 1.3(16.6-23.4)$ & 22.8 \\
Growth rate (cm/d) & $0.9 \pm 0.8$ & $1.2 \pm 0.1$ & $1.0 \pm 0.1(0.8-1.5)$ & 3.4 \\
\hline
\end{tabular}

Values are presented as mean \pm standard deviation (SD) or mean \pm SD (range), percent only.

${ }^{2)}$ Growth chamber trait values are averages from two experiments.

${ }^{y)}$ Broad-sense heritability $\left(\mathrm{H}^{2}=\mathrm{V}_{\mathrm{G}} / \mathrm{V}_{\mathrm{P}}=\right.$ total genetic variance/total phenotypic variance $)$.

$*$,**Significance at the $5 \%$ and $1 \%$ levels, respectively.

A.

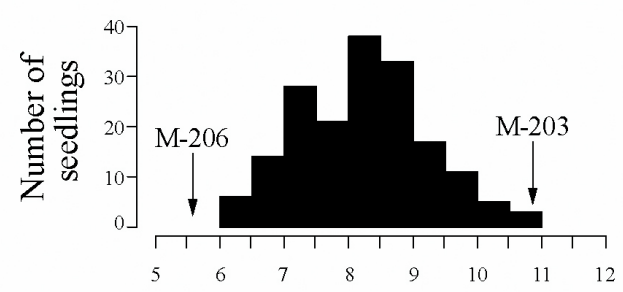

Height early seedling $(\mathrm{cm})$

C.

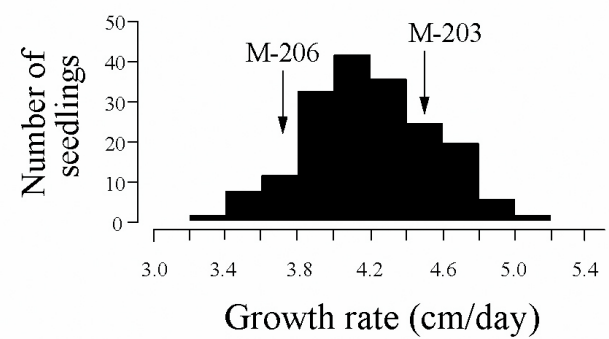

B.

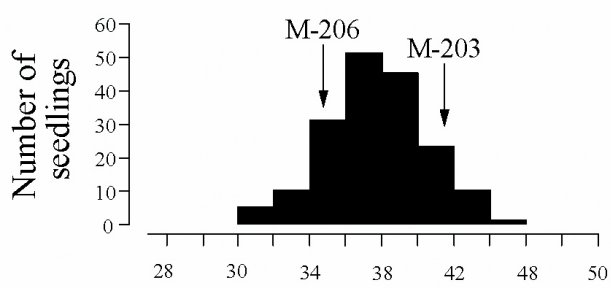

Height late seedling $(\mathrm{cm})$

D.

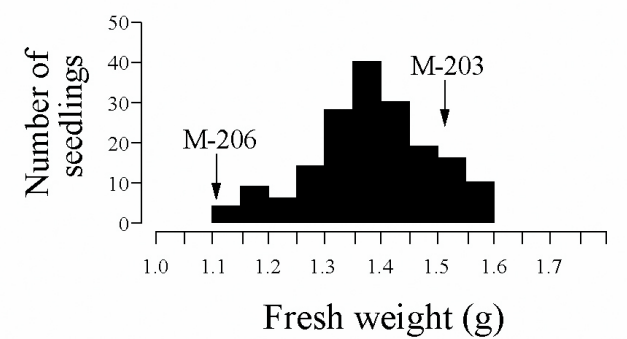

Fig. 1. Frequency distributions of the four seedling vigor-associated traits among the M-2036 recombinant inbred line population grown in a growth chamber environment (based on an average of two experiments). Mean values of parents are indicated by arrows. Number of seedlings indicated on the y-axis. 


\section{HLS and GR.}

Outdoor basin-based evaluations were conducted in June 2015 and May 2016 for three traits (HES, HLS, and GR). In 2015, the prevailing temperature conditions were typical for local field environments during rice planting season. Under these conditions, M-203 exhibited significantly better performance than M-206 for the HES trait only (Table 1). Normal distributions and transgressive segregation were observed in the population for all three traits evaluated under these conditions (Fig. 2A-C). In 2016, phenotyping was carried out in late May in which temperature (T) conditions were cooler than the 2015 season during the first 20 days of growth (2015 averages: $\mathrm{T}_{\max } 33.6^{\circ} \mathrm{C}, \mathrm{T}_{\min } 13.8^{\circ} \mathrm{C} ; 2016$ averages: $\mathrm{T}_{\max } 28.9^{\circ} \mathrm{C}$, $\mathrm{T}_{\min } 12.3^{\circ} \mathrm{C}$; meteorological data from University of California Statewide Integrated Pest Management Program, www.ipm.ucanr.edu/WEATHER/). Frequency distributions in 2016 were similar to those obtained in 2015 for HES and HLS (Fig. 2D, E). This was not the case for GR in 2016 and M-206 actually performed somewhat better than M-203 (Fig. 2F). However, there was no significant difference between the two parents for the three traits in 2016 (Table 1). As would be expected, plant growth was considerably reduced in the outdoor basins compared to the growth chamber (Table 1), likely the results of low night time temperatures. Broad-sense heritability values for HES, HLS and GR were very similar in 2015 and 2016 and were around $20 \%$ for HES and HLS and 3\% for GR.

To examine the relationships of the four seedling-vigor associated traits (HES, HLS, GR, and FW), correlation analysis was conducted (Table 2). This analysis revealed strong positive correlations between HLS and both FW $(r=0.757)$ and GR $(r=0.935)$ evaluated in the growth chamber environment. In contrast to HLS, HES showed weak correlation with GR in this environment $(r=0.193)$. The GR and FW of seedlings grown in the controlled environment exhibited a strongly positive correlation $(r=0.660)$. HLS in the growth chamber also exhibited moderate to strong positive correlation with HES and HLS in the outdoor basin 2016 environment $(r=0.566$ and 0.573 , respectively). Among the traits evaluated in the outdoor basin environments, HES and HLS exhibited strong positive correlations within each year ( $r=0.802$ for 2015; $r=0.819$ for 2016), but only moderate to weak correlations were observed for the remaining trait comparisons. Considering the growth chamber and outside basin environments together, there were generally positive correlations for all traits were commonly examined (i.e., HES, HLS,
A.

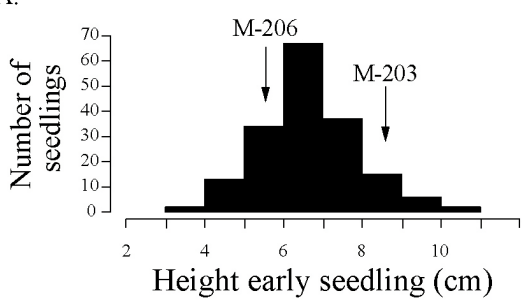

D.

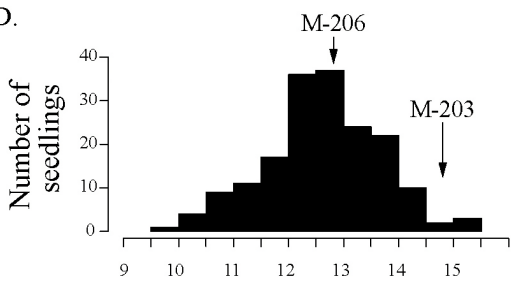

Height early seedling $(\mathrm{cm})$
B.

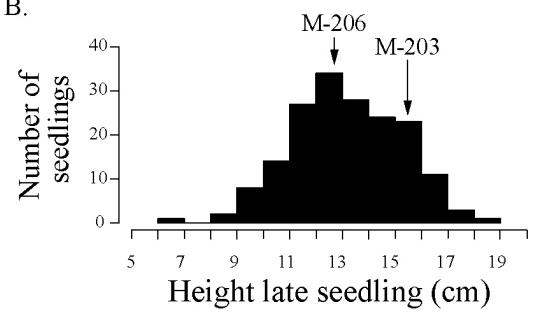

E

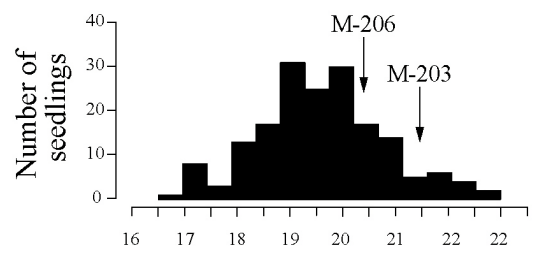

Height late seedling $(\mathrm{cm})$
C.

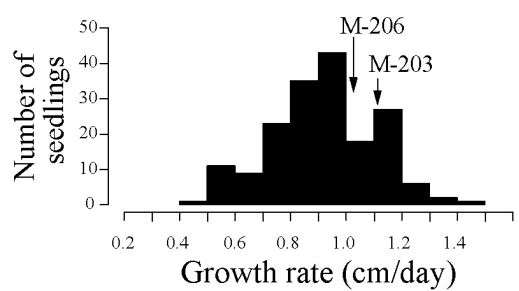

F.

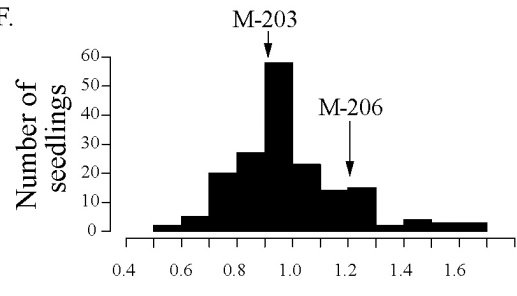

Growth rate (cm/day)

Fig. 2. Frequency distributions of three seedling vigor-associated traits among the M-2036 recombinant inbred line population grown in outdoor basins in 2015 (A-C) and 2016 (D-F). Mean values of parents are indicated by arrows. Number of seedlings indicated on the y-axis. 
Table 2. Pearson's correlation coefficients among seedling vigor-associated traits in M-2036 recombinant inbred lines.

\begin{tabular}{|c|c|c|c|c|c|c|c|c|c|c|c|}
\hline \multirow[b]{2}{*}{ Trait } & \multirow[b]{2}{*}{ Environment } & \multicolumn{3}{|c|}{ Height early seedling } & \multicolumn{3}{|c|}{ Hight late seedling } & \multicolumn{3}{|c|}{ Growth rate } & \multirow{2}{*}{$\begin{array}{c}\begin{array}{c}\text { Fresh } \\
\text { weight }\end{array} \\
\begin{array}{c}\text { Growth } \\
\text { chamber }\end{array}\end{array}$} \\
\hline & & $\begin{array}{l}\text { Outdoor } \\
\text { basin } \\
(2015)\end{array}$ & $\begin{array}{l}\text { Outdoor } \\
\text { basin } \\
(2016)\end{array}$ & $\begin{array}{l}\text { Growth } \\
\text { chamber }\end{array}$ & $\begin{array}{l}\text { Outdoor } \\
\text { basin } \\
(2015)\end{array}$ & $\begin{array}{l}\text { Outdoor } \\
\text { basin } \\
(2016)\end{array}$ & $\begin{array}{l}\text { Growth } \\
\text { chamber }\end{array}$ & $\begin{array}{l}\text { Outdoor } \\
\text { basin } \\
(2015)\end{array}$ & $\begin{array}{l}\text { Outdoor } \\
\text { basin } \\
(2016)\end{array}$ & $\begin{array}{l}\text { Growth } \\
\text { chamber }\end{array}$ & \\
\hline \multirow[t]{3}{*}{$\begin{array}{l}\text { Height early } \\
\text { seedling }\end{array}$} & $\begin{array}{l}\text { Outdoor basin } \\
\text { (2015) }\end{array}$ & 1.000 & & & & & & & & & \\
\hline & $\begin{array}{l}\text { Outdoor basin } \\
\text { (2016) }\end{array}$ & $0.314^{* *}$ & 1.000 & & & & & & & & \\
\hline & $\begin{array}{l}\text { Growth } \\
\text { chamber }\end{array}$ & $0.367^{* *}$ & $0.447^{* *}$ & 1.000 & & & & & & & \\
\hline \multirow[t]{3}{*}{$\begin{array}{l}\text { Hight late } \\
\text { seedling }\end{array}$} & $\begin{array}{l}\text { Outdoor basin } \\
\text { (2015) }\end{array}$ & $0.802 * *$ & $0.263^{* *}$ & $0.365^{* *}$ & 1.000 & & & & & & \\
\hline & $\begin{array}{l}\text { Outdoor basin } \\
\text { (2016) }\end{array}$ & $0.276^{* *}$ & $0.819^{* *}$ & $0.407 * *$ & $0.234 * *$ & 1.000 & & & & & \\
\hline & $\begin{array}{l}\text { Growth } \\
\text { chamber }\end{array}$ & $0.367 * *$ & $0.566^{* *}$ & $0.529 * *$ & $0.273^{* *}$ & $0.573 * *$ & 1.000 & & & & \\
\hline \multirow[t]{3}{*}{ Growth rate } & $\begin{array}{l}\text { Outdoor basin } \\
\text { (2015) }\end{array}$ & $0.294 * *$ & 0.107 & $0.220^{* *}$ & $0.807^{* *}$ & 0.102 & 0.075 & 1.000 & & & \\
\hline & $\begin{array}{l}\text { Outdoor basin } \\
\text { (2016) }\end{array}$ & -0.001 & 0.029 & 0.089 & 0.006 & $0.299 * *$ & 0.129 & 0.017 & 1.000 & & \\
\hline & $\begin{array}{l}\text { Growth } \\
\text { chamber }\end{array}$ & $0.268^{* *}$ & $0.466^{* *}$ & $0.193^{*}$ & $0.162^{*}$ & $0.491^{* *}$ & $0.935^{* *}$ & -0.004 & 0.111 & 1.000 & \\
\hline Fresh weight & $\begin{array}{l}\text { Growth } \\
\text { chamber }\end{array}$ & $0.335^{* *}$ & $0.497^{* *}$ & $0.513 * *$ & $0.271^{* *}$ & $0.425^{* *}$ & $0.757^{* *}$ & 0.100 & -0.039 & $0.660^{* *}$ & 1.000 \\
\hline
\end{tabular}

*** Significant at the $5 \%$ and $1 \%$ levels, respectively.

and GR) with the notable exception of GR in the outdoor basin 2016 experiment which showed no correlation with HES in any environment and HLS in the growth chamber and the outdoor basin 2015 .

\section{GBS of the M-2036 RIL population and linkage map construction}

GBS (Elshire et al. 2011) was performed on the parental lines and 190 M-2036 RILs including the 176 lines used for seedling vigor trait evaluation (Supplementary Fig. S1). A total of 226,231,217 QC-passed barcoded reads were generated from 236,562,652 raw reads from two libraries. Each sample contained on average 1,178,2887.59 qualified reads. Out of a total $1,103,450$ tags, $87 \%(n=959,840)$ were uniquely aligned and subjected to further analysis. The rest of tags aligned to multiple sites $(8.6 \%, \mathrm{n}=94,871)$ or were unaligned $(4.4 \%, \mathrm{n}=48,739)$. A total of 103,233 SNPs were discovered using reference genome japonica rice cv. Nipponbare version 7. More filtering was done to eliminate all monomorphic SNPs between parental lines M-203 and M-206, all SNPs with indels, and all the SNPs showing more than $25 \%$ of missing genotypes per site. After completion of the filtering process, 6,332 SNPs were used for QTL analysis of the 176 RILs and the two parents using the R/QTL package as described by Spindel et al. (2013). The total number of SNP markers for each chromosome (1 to 12) were: $704,508,469,483,305,435,745,628,405$, 357, 1,018, and 275 (Supplementary Fig. S2). The percent of total genotype was 91.1 and genotypic composition of M-203 and M-206 alleles were $50.7 \%$ and $49.3 \%$, respectively.

\section{QTL analysis of seedling vigor-associated traits}

QTL analysis were performed using phenotypic data collected from the grown chamber-based evaluation which included plant HES and HLS stage (defined for the growth chamber environment as seven and 14 DAS, respectively), GR (defined as HLS minus HES divided by seven days), and FW of aboveground biomass. For the outdoor basin experiments, data HES, HLS, and GR were used. As the outdoor basin conditions were not controlled, evaluation of HES was performed about seven days later than the growth 
chamber as a result of slower growth due to temperature variations.

A total of eight highly significant QTLs (LOD > 3.4) were detected over the four traits measured and the phenotypic variance explained (PVE) ranged from $7.2 \%$ to
$34.6 \%$ (Table 3). Six of the eight were from the growth chamber experiments including the largest effect QTL $q F W 1$ (LOD 18.38; 34.6\% PVE). The beneficial allele for $q F W 1$ was contributed by the higher vigor parent M-203. Two of the six QTL, $q F W 1$ and $q H E S 1$ (8.7\% PVE),

Table 3. Significant QTL for four seedling vigor-associated traits evaluated in the M-2036 RIL population.

\begin{tabular}{|c|c|c|c|c|c|c|c|c|c|c|c|c|}
\hline Trait $^{2)}$ & QTL & Location $^{\mathrm{y})}$ & Chr. & $\begin{array}{l}\text { Peak marker } \\
(\mathrm{Mb} \text { pos })\end{array}$ & $\begin{array}{c}\text { Flanking } \\
\text { markers L }\end{array}$ & $\begin{array}{c}\text { Flanking } \\
\text { markers } \mathrm{R}\end{array}$ & LOD & LOD L & LOD R & $\begin{array}{c}\mathrm{PVE}^{\mathrm{x}} \\
(\%)\end{array}$ & $\begin{array}{l}\text { Additive } \\
\text { effect }^{\mathrm{w})}\end{array}$ & $P$-value \\
\hline \multirow[t]{3}{*}{ HES } & qHES1 & GC & 1 & S1_42643480 (42.643) & S1_41353426 & S1_43245089 & 3.48 & 2.25 & 2.93 & 8.72 & -4.08 & $6.97 \mathrm{E}-05$ \\
\hline & qHES8 & $\mathrm{OB}^{2016}$ & 8 & S8_7166014 (7.166) & S8_7137579 & S8_7199162 & 5.64 & 3.40 & 3.78 & 12.31 & 5.25 & $4.53 \mathrm{E}-07$ \\
\hline & qHES9 & $\mathrm{OB}^{2016}$ & 9 & S9_6281313/38 (6.281) & S9_6272219 & S9_6528054 & 4.37 & 0.19 & 0.14 & 9.38 & -4.58 & $8.93 \mathrm{E}-06$ \\
\hline \multirow[t]{2}{*}{ HLS } & $q H L S 10$ & $\mathrm{GC}$ & 10 & S10_7040145 (7.040) & S10_6739010 & S10_7116124 & 4.99 & 0.05 & 0.45 & 10.99 & -4.91 & 2.07E-06 \\
\hline & qHLS12 & $\mathrm{GC}$ & 12 & S12_25678583 (25.679) & $\mathrm{S} 12 \_4668462$ & S12_25690880 & 4.37 & 0.17 & 2.49 & 9.54 & 4.58 & 8.97E-06 \\
\hline GR & $q G R 2$ & GC & 2 & S2_25400408 (25.500) & S2_19468940 & S2_25483293 & 4.33 & 0.22 & 0.47 & 10.73 & -4.57 & $9.06 \mathrm{E}-06$ \\
\hline \multirow[t]{2}{*}{ FW } & $q F W 1$ & $\mathrm{GC}$ & 1 & S1_42643337 (42.643) & S1_41880498 & S1_42702065 & 18.38 & 15.17 & 15.03 & 34.56 & -10.34 & $<2 \mathrm{e}-16$ \\
\hline & $q F W 9$ & $\mathrm{GC}$ & 9 & S9 $12236394(12.236)$ & S9 12235648 & S9 12236464 & 4.28 & 0.01 & 0.00 & 7.20 & -4.72 & $4.86 \mathrm{E}-06$ \\
\hline
\end{tabular}

${ }^{2)} \mathrm{HES}$ : height early seedling, HLS: height late seedling, GR: growth rate, FW: fresh weight.

${ }^{\mathrm{y})} \mathrm{GC}$ : growth chamber; OB2016: outdoor basins 2016.

${ }^{\mathrm{x})}$ Percent of the phenotypic variance explained (PVE).

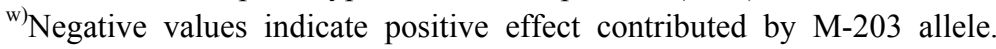

QTL: quantitative trait loci, RIL: recombinant inbred line, Chr.: chromosome, L: left, R: right, LOD: logarithm of the odds.

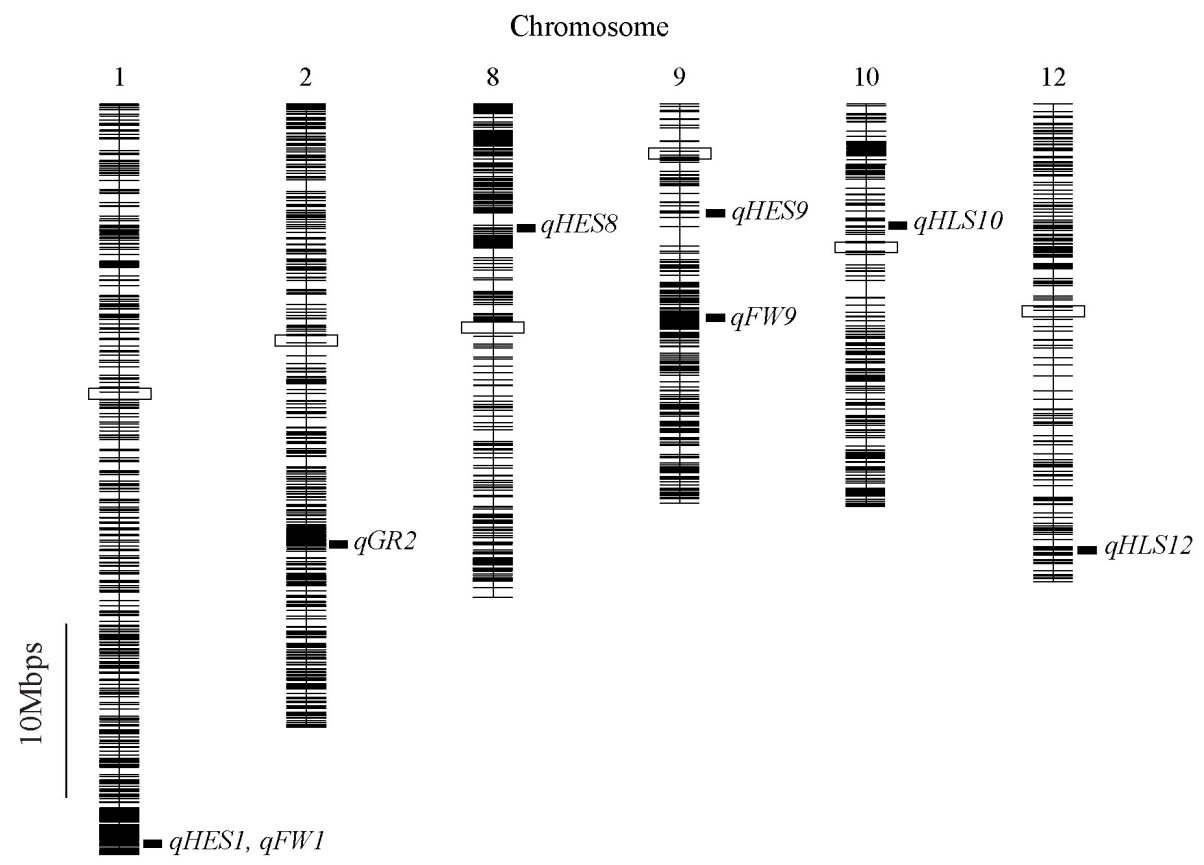

Fig. 3. Physical map of single nucleotide polymorphism markers derived from genotyping by sequencing of the M-2036 recombinant inbred line mapping population $(\mathrm{n}=176)$ and the locations of seedling vigor-associated quantitative trait locis detected in this study.

HES: height early seedling stage (7 days after sowing [DAS]), HLS: height late seedling stage (14 DAS), GR: growth rate, FW: fresh weight (aboveground biomass). Rectangular boxes indicate location of centromere. 
detected in the controlled environment were located essentially in the same position near the distal end of the long arm of chromosome 1 (Fig. 3). In the growth chamber environment, QTL were detected for all traits evaluated. With the exception of $q F W 1$, these QTL explained between $7 \%$ and $11 \%$ of the phenotypic variation observed for each trait. The positive effect for each QTL was derived from the M-203 allele except for $q H L S 12$.

The two remaining QTL were detected in the outdoor basin 2016 experiment while no QTL were detected in 2015. Both of these QTL were involved with the HES trait with the positive contribution at qHES8 (12.3\% PVE) coming from M-206 and at qHES9 (9.4\% PVE) from M-203. Of the three traits (HES, HLS, and GR) evaluated in the outdoor basin environments, the parental lines only exhibited a significant difference in HES in the outdoor basin 2015 experiment with M-203 exhibiting greater early seedling height than M-206.

\section{Evaluation of seedling vigor-associated traits in selected RILs}

Based on the growth chamber and outdoor basin evaluations of the M-2036 RIL population, a small set of high and low seedling vigor RILs were selected for further evaluation including an examination of root growth. Experiments were conducted under constant $\left(28^{\circ} \mathrm{C}\right)$ and alternating $\left(28^{\circ} \mathrm{C} / 13^{\circ} \mathrm{C}\right)$ temperatures representing nonstress and low temperature stress conditions, respectively. Seedlings grown under non-stress conditions were evaluated for shoot and RL and weight (fresh and dry) at seven and 14 DAS (Table 4). Correlation analysis of seedling traits under these conditions revealed strong to very strong positive correlations between almost all traits at the early seedling stage (seven DAS) with the exception of root dry weight (RDW) which was strongly correlated with root fresh weight (RFW) but only moderately correlated

Table 4. Seedling vigor-associated traits from selected M-2036 RILs grown under constant $\left(28^{\circ} \mathrm{C}\right)$ temperature.

\begin{tabular}{|c|c|c|c|c|c|c|c|}
\hline DAS & Line & $\mathrm{SL}(\mathrm{cm})$ & $\mathrm{RL}(\mathrm{cm})$ & SFW (mg) & RFW (mg) & SDW (mg) & RDW (mg) \\
\hline \multirow[t]{11}{*}{7} & 25 & $7.9 \pm 1.4 \mathrm{bc}$ & $18.2 \pm 3.0 \mathrm{a}$ & $37.8 \pm 7.7 \mathrm{~cd}$ & $58.7 \pm 25.7 \mathrm{bcd}$ & $4.5 \pm 1.1 \mathrm{de}$ & $4.9 \pm 1.6 \mathrm{ab}$ \\
\hline & 49 & $5.8 \pm 1.0 \mathrm{~d}$ & $14.2 \pm 6.3 \mathrm{ab}$ & $33.5 \pm 5.0 \mathrm{~d}$ & $51.9 \pm 15.9 \mathrm{~cd}$ & $4.2 \pm 0.7 \mathrm{e}$ & $4.4 \pm 0.7 b$ \\
\hline & 77 & $6.7 \pm 0.5 \mathrm{~cd}$ & $14.0 \pm 5.2 \mathrm{ab}$ & $38.4 \pm 3.3 \mathrm{~cd}$ & $61.3 \pm 18.6 \mathrm{abcd}$ & $4.6 \pm 0.3 \mathrm{cde}$ & $5.3 \pm 1.6 \mathrm{ab}$ \\
\hline & 138 & $9.5 \pm 1.6 \mathrm{ab}$ & $17.8 \pm 1.7 \mathrm{a}$ & $51.5 \pm 10.0 \mathrm{ab}$ & $80.6 \pm 14.8 \mathrm{ab}$ & $6.1 \pm 1.1 \mathrm{abc}$ & $6.7 \pm 1.2 \mathrm{a}$ \\
\hline & 149 & $9.6 \pm 1.1 \mathrm{ab}$ & $19.0 \pm 3.1 \mathrm{a}$ & $44.8 \pm 7.2 \mathrm{bcd}$ & $59.6 \pm 10.9 \mathrm{bcd}$ & $5.8 \pm 1.0 \mathrm{abcd}$ & $5.4 \pm 0.8 \mathrm{ab}$ \\
\hline & 172 & $10.6 \pm 2.5 \mathrm{a}$ & $20.7 \pm 2.9 a$ & $50.0 \pm 11.1 \mathrm{abc}$ & $73.8 \pm 5.7 \mathrm{abc}$ & $6.5 \pm 1.4 \mathrm{ab}$ & $5.7 \pm 1.0 \mathrm{ab}$ \\
\hline & 187 & $9.9 \pm 0.7 \mathrm{ab}$ & $20.2 \pm 2.4 \mathrm{a}$ & $53.6 \pm 6.3 \mathrm{ab}$ & $85.1 \pm 12.6 \mathrm{a}$ & $6.4 \pm 0.8 \mathrm{ab}$ & $5.4 \pm 0.6 \mathrm{ab}$ \\
\hline & 196 & $8.5 \pm 1.9 \mathrm{bc}$ & $18.2 \pm 3.2 \mathrm{a}$ & $41.2 \pm 8.9 \mathrm{bcd}$ & $59.6 \pm 8.5 \mathrm{bcd}$ & $5.3 \pm 1.3 \mathrm{bcde}$ & $4.0 \pm 0.9 b$ \\
\hline & 231 & $9.0 \pm 0.9 \mathrm{ab}$ & $14.7 \pm 5.7 \mathrm{ab}$ & $45.3 \pm 7.9 \mathrm{bcd}$ & $56.0 \pm 16.2 \mathrm{~cd}$ & $5.7 \pm 1.0 \mathrm{abcd}$ & $4.6 \pm 1.3 b$ \\
\hline & M-206 & $6.6 \pm 1.8 \mathrm{~cd}$ & $9.6 \pm 2.8 b$ & $38.0 \pm 15.9 \mathrm{~cd}$ & $48.0 \pm 23.4 \mathrm{~d}$ & $4.3 \pm 1.4 \mathrm{de}$ & $4.5 \pm 2.2 b$ \\
\hline & M-203 & $10.9 \pm 1.1 \mathrm{a}$ & $17.9 \pm 9.2 \mathrm{a}$ & $60.7 \pm 7.2 \mathrm{a}$ & $69.7 \pm 16.9 \mathrm{abcd}$ & $7.1 \pm 0.8 \mathrm{a}$ & $5.4 \pm 1.4 \mathrm{ab}$ \\
\hline \multirow[t]{11}{*}{14} & 25 & $41.4 \pm 4.5 \mathrm{ab}$ & $22.3 \pm 3.6 \mathrm{abc}$ & $273.6 \pm 46.1 \mathrm{ab}$ & $286.1 \pm 57.9 \mathrm{abc}$ & $48.9 \pm 8.8 \mathrm{a}$ & $26.1 \pm 7.0 \mathrm{a}$ \\
\hline & 49 & $27.7 \pm 3.7 \mathrm{~cd}$ & $16.0 \pm 1.3 \mathrm{c}$ & $172.4 \pm 35.6 \mathrm{c}$ & $177.2 \pm 63.0 \mathrm{~d}$ & $31.9 \pm 7.1 \mathrm{~b}$ & $16.6 \pm 5.6 \mathrm{ab}$ \\
\hline & 77 & $26.6 \pm 7.3 \mathrm{~d}$ & $21.1 \pm 9.5 \mathrm{abc}$ & $180.5 \pm 83.6 \mathrm{c}$ & $196.3 \pm 114 \mathrm{~cd}$ & $32.4 \pm 16.3 b$ & $15.9 \pm 8.9 b$ \\
\hline & 138 & $38.7 \pm 11 \mathrm{ab}$ & $19.3 \pm 6.2 b c$ & $245.3 \pm 101.8 \mathrm{abc}$ & $228.1 \pm 122.3 \mathrm{bcd}$ & $42.5 \pm 19.8 \mathrm{ab}$ & $20.2 \pm 13.4 \mathrm{ab}$ \\
\hline & 149 & $40.3 \pm 2.4 \mathrm{ab}$ & $23.9 \pm 2.4 \mathrm{abc}$ & $284.9 \pm 55.1 \mathrm{ab}$ & $294.6 \pm 75.6 \mathrm{abc}$ & $49.4 \pm 10.6 \mathrm{a}$ & $21.6 \pm 5.5 \mathrm{ab}$ \\
\hline & 172 & $39.2 \pm 2.6 \mathrm{ab}$ & $23.4 \pm 9.8 \mathrm{abc}$ & $237.6 \pm 50.8 \mathrm{abc}$ & $256.9 \pm 56.1 \mathrm{bcd}$ & $45.1 \pm 7.9 \mathrm{ab}$ & $20.4 \pm 3.5 \mathrm{ab}$ \\
\hline & 187 & $43.4 \pm 5.1 \mathrm{a}$ & $31.0 \pm 3.2 \mathrm{a}$ & $318.2 \pm 71.7 \mathrm{a}$ & $373.9 \pm 77.8 \mathrm{a}$ & $55.5 \pm 9.4 \mathrm{a}$ & $26.3 \pm 5.2 \mathrm{ab}$ \\
\hline & 196 & $40.8 \pm 5.4 \mathrm{ab}$ & $26.8 \pm 9.9 \mathrm{ab}$ & $282.7 \pm 69.4 \mathrm{ab}$ & $300.1 \pm 57.8 \mathrm{abc}$ & $50.6 \pm 13.0 \mathrm{a}$ & $21.5 \pm 5.8 \mathrm{ab}$ \\
\hline & 231 & $37.8 \pm 2.3 \mathrm{ab}$ & $28.9 \pm 10.3 \mathrm{ab}$ & $225.1 \pm 23.1 b c$ & $225.3 \pm 50.9 \mathrm{bcd}$ & $39.6 \pm 5.3 \mathrm{ab}$ & $16.5 \pm 4.7 \mathrm{ab}$ \\
\hline & M-206 & $35.3 \pm 4.5 b c$ & $19.3 \pm 7.1 \mathrm{bc}$ & $223.1 \pm 38.7 b c$ & $215.6 \pm 42.6 \mathrm{bcd}$ & $42.1 \pm 5.2 \mathrm{ab}$ & $16.7 \pm 4.1 \mathrm{ab}$ \\
\hline & M-203 & $38.1 \pm 4.7 \mathrm{ab}$ & $21.8 \pm 5.2 \mathrm{abc}$ & $260.1 \pm 39.6 \mathrm{abc}$ & $311.2 \pm 32.3 \mathrm{ab}$ & $46.3 \pm 6.2 \mathrm{ab}$ & $23.2 \pm 1.8 \mathrm{ab}$ \\
\hline
\end{tabular}

Different letters (a-e) indicate significant differences at $P<0.05$ by least significant difference.

RIL: recombinant inbred line, DAS: days after sowing, SL: shoot length, RL: root length, SFW: shoot fresh weight, RFW: root fresh weight, SDW: shoot dry weight, RDW: root dry weight. 
with the other traits (Supplementary Table S1). At the late seedling stage (14 DAS), all traits showed very strong positive correlation although RL was less strongly associated with the other traits, especially with RDW $(r=0.43)$. Comparison of the traits between early and late seedling stage revealed moderate to strong positive correlations of SL and RL at the early seedling stage with most traits at the late seedling stage except RL. The strongest positive correlation of traits between the seven and 14 DAS evaluations was RL at seven DAS and RDW at 14 DAS $(r=0.74)$. The shoot fresh and dry weight (SFW and SDW) and RFW at early seedling stage showed only a moderate positive correlation with all the traits at late seedling stage. The early seedling RDW showed essentially no correlation with any of the traits at the late seedling stage.

Seedlings grown under the alternating temperature conditions exhibited a significant delay in growth due to the low temperature stress conditions. As such, the seedling growth achieved at seven DAS under constant $28^{\circ} \mathrm{C}$ was not reached until 21 DAS under alternate temperature conditions (Table 5). Correlation analysis revealed mostly similar relationships between traits evaluated at early seedling stage (14 DAS for alternating conditions) as in the non-stress conditions (Supplementary Table S1). The notable exceptions were between RL and the shoot traits (SL, SFW, and SDW) which showed no correlation. Analysis of traits at late seedling stage (21 DAS) revealed similar strong positive correlations as observed in the non-stress conditions at late seedling stage (14 DAS) with the exception of RL which showed no correlation with any of the other traits. When traits evaluated at 14 DAS and 21 DAS were considered together, early seedling RL showed positive correlation with late seedling RL but either no correlation (RFW) or weak to moderate negative correlation with the other traits (SL, SFW, SDW, and RDW). The

Table 5. Seedling vigor-associated traits from selected $\mathrm{M}-2036$ RILs grown under alternating $\left(28^{\circ} \mathrm{C} / 13^{\circ} \mathrm{C}\right)$ temperatures.

\begin{tabular}{|c|c|c|c|c|c|c|c|}
\hline DAS & Line & $\mathrm{SL}(\mathrm{cm})$ & $\mathrm{RL}(\mathrm{cm})$ & SFW (mg) & RFW (mg) & SDW (mg) & RDW (mg) \\
\hline \multirow[t]{11}{*}{14} & 25 & $7.7 \pm 4.7 \mathrm{abc}$ & $12 \pm 1.8 \mathrm{ab}$ & $31.7 \pm 11.9 \mathrm{bcd}$ & $42.3 \pm 35.3 \mathrm{ab}$ & $4.7 \pm 2.1 \mathrm{abc}$ & $2.9 \pm 0.9 \mathrm{bc}$ \\
\hline & 49 & $5.2 \pm 3.0 \mathrm{~d}$ & $11.7 \pm 6.4 \mathrm{ab}$ & $23.2 \pm 11.3 \mathrm{de}$ & $32.1 \pm 14.4 b c$ & $3.1 \pm 1.7 \mathrm{~cd}$ & $3.2 \pm 1.3 \mathrm{ab}$ \\
\hline & 77 & $6.3 \pm 3.2 \mathrm{~cd}$ & $11.2 \pm 5.8 \mathrm{ab}$ & $26.3 \pm 12.5 \mathrm{cde}$ & $34.5 \pm 18.9 b c$ & $3.7 \pm 1.5 \mathrm{~cd}$ & $3.1 \pm 1.4 \mathrm{ab}$ \\
\hline & 138 & $6.6 \pm 3.7 \mathrm{~cd}$ & $12.4 \pm 1.6 \mathrm{ab}$ & $27.8 \pm 6.6 \mathrm{cde}$ & $42.5 \pm 13.8 \mathrm{ab}$ & $4.4 \pm 0.9 \mathrm{bc}$ & $3.6 \pm 0.5 \mathrm{ab}$ \\
\hline & 149 & $7.5 \pm 4.3 \mathrm{abc}$ & $12.5 \pm 2.1 \mathrm{ab}$ & $32.2 \pm 16.5 \mathrm{abcd}$ & $35.9 \pm 22.1 \mathrm{abc}$ & $4.5 \pm 2.6 b c$ & $2.8 \pm 1.2 \mathrm{bc}$ \\
\hline & 172 & $7.9 \pm 2.4 \mathrm{abc}$ & $9.3 \pm 2.9 \mathrm{ab}$ & $38.0 \pm 6.5 \mathrm{abc}$ & $48.4 \pm 11.1 \mathrm{ab}$ & $5.8 \pm 1.1 \mathrm{ab}$ & $3.9 \pm 0.4 \mathrm{ab}$ \\
\hline & 187 & $9.1 \pm 4.3 \mathrm{ab}$ & $9.2 \pm 3.9 \mathrm{ab}$ & $40.9 \pm 10.7 \mathrm{ab}$ & $34.9 \pm 9.7 \mathrm{bc}$ & $5.8 \pm 1.5 \mathrm{ab}$ & $3.0 \pm 0.8 \mathrm{bc}$ \\
\hline & 196 & $5.8 \pm 6.6 \mathrm{~cd}$ & $6.5 \pm 4.1 b$ & $15.2 \pm 11.2 \mathrm{e}$ & $16.1 \pm 18.9 \mathrm{c}$ & $1.9 \pm 2.1 \mathrm{~d}$ & $1.5 \pm 1.4 \mathrm{c}$ \\
\hline & 231 & $7.0 \pm 5.0 \mathrm{bcd}$ & $12.9 \pm 7.1 \mathrm{ab}$ & $30.7 \pm 11.0 \mathrm{bcd}$ & $38.4 \pm 19.1 \mathrm{abc}$ & $4.5 \pm 2.0 \mathrm{bc}$ & $4.0 \pm 2.1 \mathrm{ab}$ \\
\hline & M-206 & $5.6 \pm 3.5 \mathrm{~cd}$ & $14.8 \pm 11.3 \mathrm{a}$ & $24.1 \pm 3.6 \mathrm{de}$ & $32.1 \pm 6.6 \mathrm{bc}$ & $3.5 \pm 0.6 \mathrm{~cd}$ & $2.9 \pm 0.5 \mathrm{bc}$ \\
\hline & M-203 & $9.4 \pm 3.6 \mathrm{a}$ & $11.5 \pm 2.9 \mathrm{ab}$ & $44.7 \pm 13.0 \mathrm{a}$ & $59.3 \pm 16.1 \mathrm{a}$ & $6.6 \pm 1.8 \mathrm{a}$ & $4.6 \pm 0.5 \mathrm{a}$ \\
\hline \multirow[t]{11}{*}{21} & 25 & $10.9 \pm 2.5 \mathrm{ab}$ & $15.6 \pm 3.8 \mathrm{ab}$ & $59.3 \pm 14.6 a b c$ & $69 \pm 14.9 \mathrm{abc}$ & $12 \pm 2.7 \mathrm{a}$ & $8.1 \pm 2.0 \mathrm{abc}$ \\
\hline & 49 & $6.3 \pm 2.2 \mathrm{c}$ & $15.2 \pm 4.1 \mathrm{ab}$ & $37.8 \pm 19.6 \mathrm{~d}$ & $49.7 \pm 19.1 \mathrm{c}$ & $7.1 \pm 3.2 b$ & $5.8 \pm 2.0 \mathrm{~cd}$ \\
\hline & 77 & $7.7 \pm 2.3 \mathrm{c}$ & $14.9 \pm 4.4 \mathrm{ab}$ & $41.6 \pm 19.0 \mathrm{~cd}$ & $49.5 \pm 7.6 \mathrm{c}$ & $8.1 \pm 3.0 \mathrm{~b}$ & $6.1 \pm 1.2 \mathrm{~cd}$ \\
\hline & 138 & $11.4 \pm 1.1 \mathrm{ab}$ & $14.7 \pm 4.4 \mathrm{ab}$ & $77.5 \pm 13.7 \mathrm{a}$ & $75.5 \pm 14.9 \mathrm{abc}$ & $14.9 \pm 2.9 \mathrm{a}$ & $8.1 \pm 1.6 \mathrm{abc}$ \\
\hline & 149 & $10.1 \pm 2.2 b$ & $15.9 \pm 5.6 \mathrm{ab}$ & $66.5 \pm 21.4 \mathrm{a}$ & $67.4 \pm 16.8 \mathrm{abc}$ & $13.5 \pm 4.1 \mathrm{a}$ & $7.5 \pm 1.5 \mathrm{bcd}$ \\
\hline & 172 & $10.1 \pm 0.9 b$ & $15.2 \pm 3.8 \mathrm{ab}$ & $66 \pm 17.4 \mathrm{a}$ & $76.3 \pm 3.9 \mathrm{ab}$ & $12.6 \pm 2.0 \mathrm{a}$ & $9.3 \pm 1.1 \mathrm{ab}$ \\
\hline & 187 & $12.8 \pm 2.7 \mathrm{a}$ & $11.5 \pm 0.7 b$ & $76.8 \pm 19.0 \mathrm{a}$ & $70.5 \pm 23.9 \mathrm{abc}$ & $14.8 \pm 2.6 \mathrm{a}$ & $7.4 \pm 2.5 \mathrm{bcd}$ \\
\hline & 196 & $11.0 \pm 2.9 \mathrm{ab}$ & $13.9 \pm 5.8 \mathrm{ab}$ & $64.3 \pm 25.7 \mathrm{a}$ & $60.0 \pm 25.0 \mathrm{bc}$ & $12.6 \pm 3.9 \mathrm{a}$ & $7.1 \pm 3.0 \mathrm{bcd}$ \\
\hline & 231 & $10.2 \pm 2.6 b$ & $20.7 \pm 8.3 a$ & $61.7 \pm 29.1 \mathrm{ab}$ & $72.7 \pm 14.8 \mathrm{abc}$ & $12.6 \pm 5.4 \mathrm{a}$ & $8.4 \pm 1.0 \mathrm{abc}$ \\
\hline & M-206 & $6.8 \pm 3.5 \mathrm{c}$ & $17.1 \pm 10.3 \mathrm{ab}$ & $44.4 \pm 29.3 \mathrm{bcd}$ & $54.4 \pm 34.8 b c$ & $8.3 \pm 6.2 b$ & $5.0 \pm 3.2 \mathrm{~d}$ \\
\hline & M-203 & $11.6 \pm 3.9 \mathrm{ab}$ & $15.5 \pm 3.2 \mathrm{ab}$ & $73.9 \pm 36.2 \mathrm{a}$ & $89.2 \pm 20.8 \mathrm{a}$ & $14.9 \pm 6.0 \mathrm{a}$ & $10.5 \pm 1.7 \mathrm{a}$ \\
\hline
\end{tabular}

Different letters (a-e) indicate significant differences at $P<0.05$ by least significant difference.

RIL: recombinant inbred line, DAS: days after sowing, SL: shoot length, RL: root length, SFW: shoot fresh weight, RFW: root fresh weight, SDW: shoot dry weight, RDW: root dry weight. 
strongest positive correlations were observed between early SL and all late seedling traits ( $\mathrm{r}$ values from 0.73 to $0.82)$ with the exception of RL ( $r=-0.24)$ and between late seedling RFW and RDW and all early seedling traits except RL.

At the early seedling stage (seven DAS for $28^{\circ} \mathrm{C}$ and 14 DAS for $28^{\circ} \mathrm{C} / 13^{\circ} \mathrm{C}$ ), it was observed that $\mathrm{M}-203$ had significantly longer roots than M-206 under the constant temperature conditions and significantly heavier roots (fresh and dry weight) under the alternating temperature conditions (Table 4, 5). Under favorable conditions (constant $28^{\circ} \mathrm{C}$ ), the parental lines exhibited no significant differences for all the traits measured at 14 DAS. Only RIL-187 was significantly superior to all the low vigor lines (RIL-49, RIL-77, and M-206) for four of the traits measured (SL, RL, shoot FW and root FW). Under low temperature stress conditions $\left(28^{\circ} \mathrm{C} / 13^{\circ} \mathrm{C}\right), \mathrm{M}-203$ was significantly superior to M-206 in all traits evaluated except RL at 14 DAS (Table 5). Analysis of the RILs revealed that under both growth conditions, RIL-187 was significantly better than M-206 and the low vigor lines for almost all the traits evaluated. In addition, most of the high vigor RILs were significantly better than M-206 and the two low vigor lines for all shoot traits but only for dry weight with respect to the root traits evaluated (Table 4). It was observed that plants which did not exhibit superior RL were generally more vigorous with respect to other traits (e.g., SL and weight) than plants with longer roots under both conditions.

\section{DISCUSSION}

Seedling vigor is an important trait for rice breeding programs tasked with the development of varieties for direct-seeded production systems. In California, directseeding takes the form of aerially sowing pre-germinated seeds into flooded fields. Varieties bred for this production environment exhibit good early seedling vigor with respect to shoot development and emergence from the water surface. The two California medium grain rice varieties examined in this study, M-203 and M-206, are similar in many traits including seedling vigor in a water-seeded system. However, when evaluated in a dry-seeding format, it was observed that M-203 seedlings appeared to be more vigorous. To further investigate this phenomenon, we evaluated M-203 and M-206 and a RIL population derived from the two varieties under the controlled environment of a growth chamber and in an uncontrolled environment of outdoor basins. In the growth chamber environment, significant differences were observed for HES and HLS, GR, and FW with M-203 performing better than M-206. In contrast, evaluation of HES, HLS, and GR in outdoor basins revealed no significant differences with the sole exception of HES in 2015. Broad-sense heritability also reflected differences between the controlled and uncontrolled environments.

A total of eight seedling vigor-associated QTL were detected in our study, six from the growth chamber experiments and two from the outdoor basin 2016 environment. The small number of QTL detected was consistent with a previous study on seedling vigor traits in japonica rice (Yang et al. 2010) and may reflect the lower genetic diversity in our populations. Five of the six QTL detected in the growth chamber environment had minor effects with each explaining $<12 \%$ phenotypic variance observed. The one major effect QTL, $q F W 1$, was detected on chromosome 1 and contributed to about $35 \%$ of the phenotypic variation for seedling FW. qHES1 mapped to the same position as $q F W 1$ and accounts for about $9 \%$ of the phenotypic variance observed for early seedling height. The $q F W 1 / q H E S 1$ locus corresponds to a recently reported QTL for SL (Lu et al. 2016). In that study, a genome-wide association mapping approach was used to identify SL and mesocotyl elongation QTL in a population of 469 indica rice accessions under controlled environment conditions (Lu et al. 2016). The accessions were genotyped with over 4,000 SNP markers and one marker at position 41,143,657 on chromosome 1 was significantly associated with SL, explaining about $40 \%$ of the phenotypic variance observed. This is similar to the large effect that $q F W 1$ exhibited in our study (peak LOD marker at position $42,643,337$ ). These findings indicate that this region on the distal end of the long arm of chromosome 1 , which is about $4 \mathrm{Mb}$ away from the $s d l$ gene (position 38,381,339), harbors a gene or genes that contribute to seedling vigor in both indica and japonica 
rice. Given the major effect of these QTL, fine mapping and gene isolation should be relatively straightforward.

Of the three seedling vigor traits evaluated in the outdoor basins, QTL were only detected for HES in 2016. This reflects the complex nature of seedling vigor and the influence of the environment, particularly low temperature, on the traits evaluated. It should be noted that even in the controlled environment of the growth chamber, QTL for HES, HLS, and GR were of minor effect and might not be detected in the extreme conditions in the outdoor basins. Unfortunately, data for FW were not available for analysis in this study so it was not possible to determine if $q F W 1$ contributes to seedling vigor under these conditions. Although QTL were not detected across the growth chamber and the outdoor basin environments, M-2036 RILs which consistently performed better than the higher vigor parent M-203 were observed. Evaluation of selected lines under non-stress and low temperature stress conditions in a growth chamber confirmed the earlier observation that RIL-187 was among the best performers considering all traits in all environments. This line could be useful germplasm for enhancing seedling vigor in temperate japonica cultivated under dry-seeded systems. It was also observed that under low temperature stress M-203 and M-206 differed significantly in their root traits, which were not evaluated in the entire RIL population $(n=176)$. Evaluating root growth in the M-2036 RIL population may provide insight into seedling performance under low temperature stress conditions similar to outdoor basins or field environments.

Of the many QTL studies conducted on rice seedling vigor, very few have involved biparental mapping populations developed from crosses between varieties or accessions of the same rice subspecies/subpopulations. Development of DNA marker systems that have facilitated the detection of polymorphism in closely-related rice varieties (e.g., simple sequence repeats) have enabled analysis of populations that may yield information and germplasm that are more relevant to breeding. Great advances over the past decade have led to platforms that have enabled cost-effective genotyping of SNP markers in rice (Spindel et al. 2013; McCouch et al. 2016), thus providing powerful tools to investigate any population of interest. In this study, the GBS method was employed to construct an ultra-high-density SNP marker map of the M-2036 RIL population, which was developed from a very narrow rice germplasm base (Dilday 1990; Lu et al. 2005; Kim and Tai 2013, McKenzie et al. 2015). GBS enabled the identification of over 6,000 SNP markers well-distributed over the twelve rice chromosomes that will facilitate our efforts to fine map the major QTL detected in this study and to conduct analyses targeting additional components of seedling vigor.

One of the immediate goals is to determine if $q F W 1$ represents a good target for molecular breeding by determining if its effect is observed under direct dry-seeding in a field environment. This would initially involve evaluation of the M-2036 RIL population while near-isogenic lines are developed by backcrossing selected RILs (e.g., RIL-187) to the M-206 parent for further validation of the QTL and fine mapping efforts. As noted earlier, the detection of a QTL by association analysis of indica germplasm (Lu et al. 2016 ) in close proximity to $q F W 1$ supports the possible value of this region for enhancing seedling vigor and the same approach can be used to investigate $q F W 1$. Seedling FW as well as other seedling vigor-associated traits could be evaluated in well-established rice germplasm collections (e.g., Rice Diversity Panel 1 and 2) that have been extensively genotyped and used in genome-wide association studies (Zhao et al. 2011; McCouch et al. 2016) to complement validation efforts using materials derived from this study.

\section{ACKNOWLEDGEMENTS}

This work was supported by funds from USDA-ARS CRIS Project 21000-5306-021-00D and Rice Research Board RB-3 Project (2011-2014) to T.H.T. In addition, K.C.L. acknowledges BECAS Chile and CONICYT, the UC Davis Department of Plant Sciences and the Horticulture and Agronomy Graduate Group, and INIA-Chile for providing funding for her Ph.D. program. We thank Dr. V.C. Andaya (California Cooperative Rice Research Foundation, Inc.) for providing the $\mathrm{F}_{2}$ seeds from the cross M-203/M-206 for the development of the M-2036 RIL 
mapping population. We thank G. Munjal (Department of Plant Sciences, UC Davis) for consulting on R coding. GBS was facilitated by an instrument grant to Cornell University Biotechnology Resource Center, NIH 1S10OD010693-01.

\section{REFERENCES}

Abe A, Takagi H, Fujibe T, Aya K, Kojima M, Sakakibara H, et al. 2012. OsGA20ox1, a candidate gene for a major QTL controlling seedling vigor in rice. Theor. Appl. Genet. 125: 647-657.

Anandan A, Anumalla M, Pradhan SK, Ali J. 2016. Population structure, diversity and trait association analysis in rice (Oryza sativa L.) germplasm for Early Seedling Vigor (ESV) using trait linked SSR markers. PLoS One 11: e0152406.

Bradbury PJ, Zhang Z, Kroon DE, Casstevens TM, Ramdoss Y, Buckler ES. 2007. TASSEL: Software for association mapping of complex traits in diverse samples. Bioinformatics 23: 2633-2635.

Broman KW, Wu H, Sen S, Churchill GA. 2003. R/qtl: QTL mapping in experimental crosses. Bioinformatics 19: 889-890.

Cairns JE, Namuco OS, Torres R, Simborio FA, Courtois B, Aquino GA, et al. 2009. Investigating early vigour in upland rice (Oryza sativa L.): Part II. Identification of QTLs controlling early vigour under greenhouse and field conditions. Field Crops Res. 113: 207-217.

Carnahan HL, Johnson CW, Tseng ST, Oster JJ, Hill JE, Brandon DM. 1989. Registration of 'M-203' rice. Crop Sci. 29: 1089-1090.

Cheng J, He Y, Yang B, Lai Y, Wang Z, Zhang H. 2015. Association mapping of seed germination and seedling growth at three conditions in indica rice (Oryza sativa L.). Euphytica 206: 103-115.

Cui H, Peng B, Xing Z, Xu G, Yu B, Zhang Q. 2002. Molecular dissection of seedling-vigor and associated physiological traits in rice. Theor. Appl. Genet. 105: 745-753.

Dang X, Thi TG, Dong G, Wang H, Edzesi WM, Hong D. 2014. Genetic diversity and association mapping of seed vigor in rice (Oryza sativa L.). Planta 239: 1309-1319.

Dilday RH. 1990. Contribution of ancestral lines in the development of new cultivars of rice. Crop Sci. 30: 905-911.

Diwan J, Channbyregowda M, Shenoy V, Salimath P, Bhat R. 2013. Molecular mapping of early vigour related QTLs in rice. Res. J. Biol. 1: 24-30.

Elshire RJ, Glaubitz JC, Sun Q, Poland JA, Kawamoto K, Buckler ES, et al. 2011. A robust, simple genotypingby-sequencing (GBS) approach for high diversity species. PLoS One 6: e19379.

Farooq M, Siddique KHM, Rehman H, Aziz T, Lee DJ, Wahid A. 2011. Rice direct seeding: Experiences, challenges and opportunities. Soil Tillage Res. 111: $87-98$.

Glaubitz JC, Casstevens TM, Lu F, Harriman J, Elshire RJ, Sun Q, et al. 2014. TASSEL-GBS: A high capacity genotyping by sequencing analysis pipeline. PLoS One 9: e90346.

Jiang L, Xun M, Wang J, Wan J. 2008. QTL analysis of cold tolerance at seedling stage in rice (Oryza sativa L.) using recombinant inbred lines. J. Cereal Sci. 48: 173-179.

Johnson CW, inventor; California Cooperative Rice Research Foundation, Inc., assignee. 2005. Mar 10. United States Patent application publication for M-206. United States patent US 2005/0055739 A1.

Kawahara Y, de la Bastide M, Hamilton JP, Kanamori H, McCombie WR, Ouyang S, et al. 2013. Improvement of the Oryza sativa Nipponbare reference genome using next generation sequence and optical map data. Rice $(\mathrm{N}$ Y) $6: 4$.

Kim SI, Tai TH. 2013. Identification of SNPs in closely related Temperate Japonica rice cultivars using restriction enzyme-phased sequencing. PLoS One 8: e60176.

Lee HS, Sasaki K, Higashitani A, Ahn SN, Sato T. 2012. Mapping and characterization of quantitative trait loci for mesocotyl elongation in rice (Oryza sativa L.). Rice (N Y) 5: 13 .

Li H, Durbin R. 2009. Fast and accurate short read alignment with Burrows-Wheeler transform. Bioinformatics 25: 1754-1760.

Lu H, Redus MA, Coburn JR, Rutger JN, McCouch SR, Tai TH. 2005. Population structure and breeding patterns of 145 U.S. rice cultivars based on SSR marker analysis. Crop Sci. 45: 66-76.

Lu Q, Zhang M, Niu X, Wang C, Xu Q, Feng Y, et al. 2016. Uncovering novel loci for mesocotyl elongation and shoot 
length in indica rice through genome-wide association mapping. Planta 243: 645-657.

Lu XL, Niy AL, Cai HY, Zhao Y, Liu JW, Zhu YG, et al. 2007. Genetic dissection of seedling and early vigor in a recombinant inbred line population of rice. Plant Sci. 172: 212-220

Mahender A, Anandan A, Pradhan SK. 2015. Early seedling vigour, an imperative trait for direct-seeded rice: An overview on physio-morphological parameters and molecular markers. Planta 241: 1027-1050.

McCouch SR, Wright MH, Tung CW, Maron LG, McNally KL, Fitzgerald M, et al. 2016. Open access resources for genome-wide association mapping in rice. Nat. Commun. 7: 10532 .

McKenzie KS, Andaya VC, Jodari F, Samonte SOPB, Oster JJ, Andaya CB. 2015. Rice breeding at the California rice experiment station. SABRAO J. Breed. Genet. 47: 1-13.

Purcell S, Neale B, Todd-Brown K, Thomas L, Ferreira MA, Bender D, et al. 2007. PLINK: A tool set for whole-genome association and population-based linkage analyses. Am. J. Hum. Genet. 81: 559-575.

Redoña ED, Mackill DJ. 1996. Mapping quantitative trait loci for seedling vigor in rice using RFLPs. Theor. Appl. Genet. 92: 395-402.
Spindel J, Wright M, Chen C, Cobb J, Gage J, Harrington S, et al. 2013. Bridging the genotyping gap: Using genotyping by sequencing (GBS) to add high-density SNP markers and new value to traditional bi-parental mapping and breeding populations. Theor. Appl. Genet. 126: 2699-2716.

Tai TH, Tanksley SD. 1990. A rapid and inexpensive method for isolation of total DNA from dehydrated plant tissue. Plant Mol. Biol. Rep. 8: 297-303.

Wu J, Feng F, Lian X, Teng X, Wei H, Yu H, et al. 2015. Genome-wide Association Study (GWAS) of mesocotyl elongation based on re-sequencing approach in rice. BMC Plant Biol. 15: 218.

Xie L, Tan Z, Zhou Y, Xu R, Feng L, Xing Y, et al. 2014. Identification and fine mapping of quantitative trait loci for seed vigor in germination and seedling establishment in rice. J. Integr. Plant Biol. 56: 749-759.

Yang W, Yuan G, De-Lin H. 2010. Discovery of elite alleles for seed vigor traits in two populations of japonica rice in Taihu lake region. Acta Agron. Sin. 36: 754-763.

Zhao K, Tung CW, Eizenga GC, Wright MH, Ali ML, Price $\mathrm{AH}$, et al. 2011. Genome-wide association mapping reveals a rich genetic architecture of complex traits in Oryza sativa. Nat. Commun. 2: 467. 